\title{
Stinging insect allergy: current perspectives on venom immunotherapy
}

\author{
This article was published in the following Dove Press journal: \\ Journal of Asthma and Allergy \\ 23 July 2015 \\ Number of times this article has been viewed
}

\author{
Sian W Ludman' \\ Robert J Boyle ${ }^{2}$ \\ 'Paediatric Allergy Department, \\ St Mary's Hospital, Imperial \\ Healthcare NHS Trust, London, UK; \\ ${ }^{2}$ Department of Paediatrics, Imperial \\ College London, London, UK
}

\begin{abstract}
Systemic allergic reactions to insect stings affect up to 5\% of the population during their lifetime, and up to $32 \%$ of beekeepers. Such reactions can be fatal, albeit very rarely, and fear of a further systemic reaction (SR) can lead to significant anxiety and quality of life impairment. A recent Cochrane systematic review confirmed that venom immunotherapy (VIT) is an effective treatment for people who have had a systemic allergic reaction to an insect sting. VIT reduces risk of a further SR (relative risk $0.10,95 \%$ confidence interval $0.03-0.28$ ), but VIT also reduces risk of a future large local reaction, and significantly improves disease-specific quality of life. However, health economic analysis showed that VIT is generally not cost effective for preventing future SRs; most people are stung infrequently, most SRs resolve without long-term consequences, and a fatal outcome is extremely rare. VIT only becomes cost effective if one is stung frequently (eg, beekeepers) or if quality of life improvement is considered. Thus, for most people with insect sting allergy, anxiety and quality of life impairment should be the overriding consideration when making treatment decisions, highlighting the importance of a patient-centered approach. Areas which need to be explored in future research include efforts to improve the safety and convenience of VIT such as the use of sublingual immunotherapy; quality of life effects of venom allergy in children and adolescents as well as their parents; and the optimal duration of treatment.
\end{abstract}

Keywords: anaphylaxis, quality of life

\section{Background}

A variety of stinging insects can cause allergic reactions in humans. The most common are: wasps (hornets [Vespa], yellow jackets [United States]/wasps [Europe] [Vespula], paper wasp [Polistinae]), bees (honey [Apis mellifera], bumble bees [Bombus]), and stinging ants (fire ants [Solenopsis], jack jumper and bull ants [Myrmecia], and Pachycondyla). ${ }^{1}$ Their taxonomy is shown in Figure 1. Venom from the jack jumper ant is the most allergenic of the venoms and causes the highest rate of anaphylaxis. ${ }^{1}$ Honeybee stings are also generally held to be more severe than wasp stings. Bees inject $50-140 \mu \mathrm{g}$ of venom. ${ }^{2,3}$ Due to a unique barbed stinging apparatus, the bee stinger is often still attached, and venom can continue to be injected for up to 1 minute following removal of the insect. However, bees cannot sting again, whereas wasps can sting multiple times delivering $\sim 3 \mu \mathrm{g}$ of venom with each sting. ${ }^{1}$ Wasps are aggressive and sting to attack, whilst bees sting as a defensive maneuver. Most reactions manifest as a painful, erythematous swelling at the sting site.

Whilst most sting reactions are painful and annoying, they are easily dealt with and resolve quickly. Unfortunately, some people react more vigorously to stings
Correspondence: Robert J Boyle

Paediatric Research Unit, Department of Paediatrics, Imperial College London, Norfolk Place, London W2 IPG, UK Tel +442075943990

$\mathrm{Fax}+442075943984$

Email r.boyle@imperial.ac.uk 


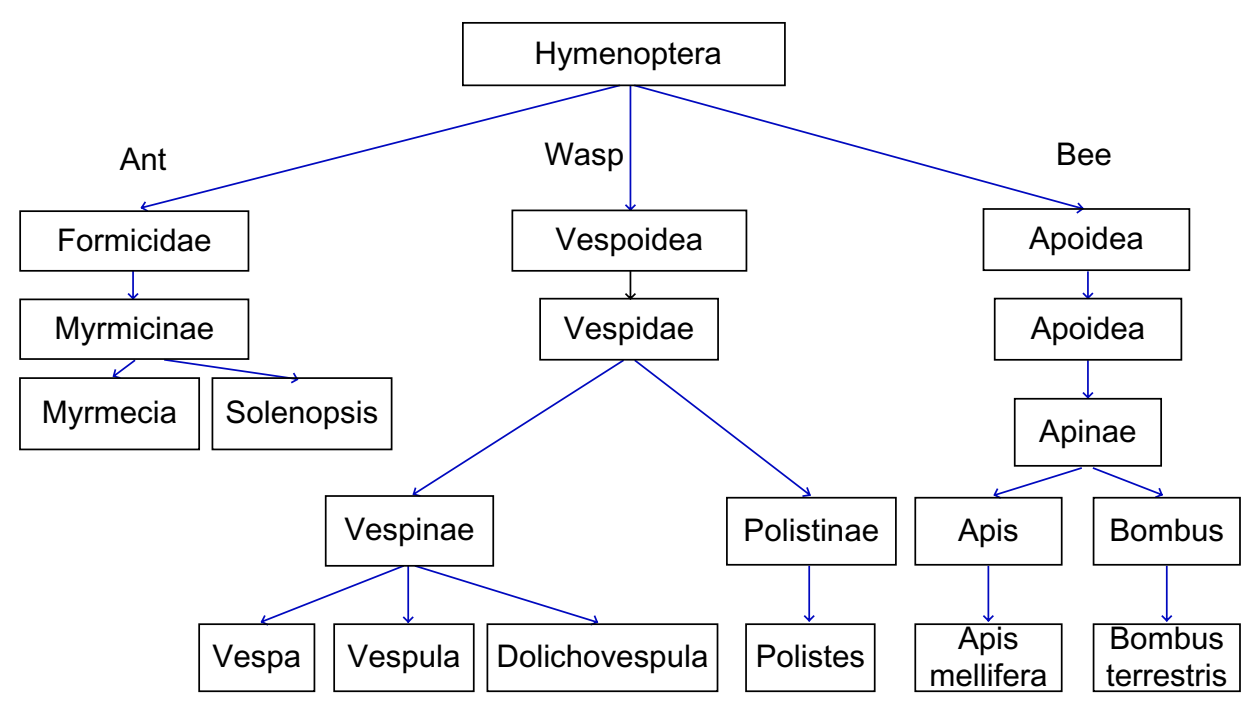

Figure I Modified taxonomic tree of stinging insects.

Notes: Data from Tan and Campbell' and Krishna et al. ${ }^{4}$

and in such a way that requires treatment. This can be as a large local reaction (LLR) ( $>10 \mathrm{~cm}$ diameter), thought to represent a late-phase $\mathrm{IgE}$ mediated allergic reaction. This can sometimes be mistaken as cellulitis as it can last up to 24-48 hours. ${ }^{5}$ Reactions which cause symptoms beyond the local site of sting are termed systemic reactions (SRs). Severe life-threatening SRs (anaphylaxis) can occur, and are termed venom anaphylaxis. If a patient experiences a LLR, there is $5 \%-10 \%$ risk of them developing a systemic allergic reaction to a sting in the future. ${ }^{5-7}$

Anaphylaxis to an insect sting is classified not only on the basis of cardiac or respiratory compromise, but also by any abdominal cramps or vomiting. This is unlike allergic reactions to food where gastrointestinal symptoms can be part of nonanaphylactic reactions, since the gastrointestinal tract is the site of allergen exposure. ${ }^{8}$ Anaphylaxis to an insect sting can cause a terrifyingly rapid death, with initial cardiorespiratory arrest within 5-10 minutes of the sting in many such cases. ${ }^{9}$ The possibility of such an event can lead to significant anxiety and social restrictions in people at risk of an allergic reaction to an insect sting.

\section{Prevalence and incidence of venom allergy}

Hypersensitivity to insect stings affects up to $5 \%-7.5 \%$ of the population and up to $32 \%$ of beekeepers. ${ }^{10}$ If a sting reaction is classified as anaphylaxis, the risk of anaphylaxis with a future sting is significantly raised, but is still less than $50 \%$ in most cases. The risk is greater in those with more severe previous venom anaphylaxis, and lower in children. ${ }^{1,11}$
The rates of venom allergy leading to hospital admission for anaphylaxis have risen since $1992 .{ }^{12}$ Venom anaphylaxis admissions appear to be increasing in the UK at a rate of $11.5 \%$ (95\% confidence interval [CI] 10.4-12.7) per year, in keeping with other forms of anaphylaxis. ${ }^{12}$ However, fatal reactions are not increasing; the increase in admissions may be due to changes in awareness, health-seeking behavior, or coding. Hospital admission for venom anaphylaxis is very rare in the first 3 decades of life and rises with increasing age. Ninety-three episodes of fatal venom anaphylaxis occurred in the UK over a 10 -year period at a mean age of 59 years, which converts to a fatality rate of 0.009 per 100,000 population per annum. ${ }^{12}$ In the US, at least 40 people per year die from insect stings. ${ }^{13}$ Overall, fatalities from sting anaphylaxis range from 0.03 to 0.48 per million inhabitants per year. Fatal venom anaphylaxis accounts for $20 \%$ of all anaphylaxis fatalities. ${ }^{14}$

Whilst this mortality rate is important and anaphylaxis is relatively common, it is interesting to note that severe immediate outcomes are rare, with only $2 \%$ of significant anaphylaxis involving cardiorespiratory arrest. ${ }^{15}$ Long-term morbidity following venom anaphylaxis has not to our knowledge been reported beyond the psychological consequences of venom allergy. Insect stings can also be fatal without leading to an allergic reaction, especially if multiple stings are delivered. ${ }^{16}$ SRs are more likely in men, older patients, patients with a raised baseline tryptase level, ${ }^{17,18}$ those taking angiotensinconverting-enzyme (ACE) inhibitors ${ }^{17,18}$ or beta blockers, ${ }^{19}$ and with physical exercise around the time of the sting, eosinophilia, ${ }^{20}$ or nonsteroidal anti-inflammatory drug ingestion. ${ }^{21}$ 
The life-time prevalence of an allergic reaction to stings in adults in America is documented as 19\% via a self-reported telephone survey. ${ }^{22}$ Of these patients, a previous allergic reaction to any substance raised the life-time prevalence of venom allergy to $41 \%$, nearly $20 \%$ of whom had confirmed anaphylaxis. European data (NORA) ${ }^{15}$ found that $20 \%$ of documented anaphylaxis was due to venom allergy in the European pediatric population. In adults, venom as the cause of anaphylaxis was $48.2 \%$. Of these, $70.6 \%$ of stings were caused by wasps, $23.4 \%$ bee, and $4.1 \%$ hornet venom. Data for the UK show venom to be a less common cause of anaphylaxis: accounting for $\sim 10 \%$ of hospital admissions for anaphylaxis at all ages, and very few cases in children. ${ }^{12}$

\section{Diagnosis of venom allergy}

Diagnosis of any allergic reaction requires a clear, thorough medical history. However, in hymenoptera venom allergy, difficulty can occur in ascertaining the type of insect sting. ${ }^{23}$ The issue is also clouded as the sensitization rate (positive tests to hymenoptera venom but with a negative history) is quite high; $25 \%-50 \%$ of people with positive specific $\operatorname{IgE}$ ( $\mathrm{s}$ IgE) or intradermal tests for venom and a positive history of insect sting reaction have a positive sting challenge. ${ }^{24}$ However, people with a clear documented history of a venom reaction can have negative tests, and occasionally testing can be positive to both honey bee and wasp venom. ${ }^{4}$

\section{Allergy skin testing}

Skin prick testing (SPT) and intradermal testing should be performed at least 2 weeks after a sting reaction, ideally 1-2 months later in case of false negatives due to a refractory period after a sting. However, the sensitivity of SPT is lower than that of intradermal testing. Increasing doses of venom traditionally have been used for either SPT or intradermal testing; initially performed at low concentrations, the level of venom is increased until a positive reaction is exhibited. ${ }^{25}$ The SPT should be performed at a concentration between 1.0 and $100 \mu \mathrm{g} / \mathrm{mL}$, and the intradermal initial concentration should be in the range of $0.001-0.01 \mu \mathrm{g} / \mathrm{mL}$. It should then increase in tenfold increments to a maximum concentration of $1.0 \mu \mathrm{g} / \mathrm{mL} .{ }^{17}$ Recent information ${ }^{26}$ suggests that simultaneous intradermal testing with different venoms is safe and efficient.

\section{slgE testing}

In vitro sIgE testing for wasp and bee allergens can supplement the clinical history and skin testing. The sensitivity of venom sIgE, as for other allergens, is generally lower than that of skin (intradermal) testing. sIgE can be performed for the whole extract or for components in the venom. These components can be natural components (nApi m 4) or recombinant allergens (rApi m 1, rVes v 1, rVes v 5, rPol d 5). ${ }^{27}$ The use of natural venom extracts can lead to clouding of the diagnostic process secondary to cross-reacting carbohydrate determinants (CCDs). Recombinant allergens can circumnavigate the issues of: double-positive tests to bee and wasps with an unclear history; patients with a negative test but a good clinical history where natural allergens may have degraded or denatured; and planning of immunotherapy. Commercially available microarray chips can measure multiple components at once, including rApi m 1, nApi m 4, rPol d 5, and rVes $\mathrm{v} 5$, to aid in venom allergy diagnosis. ${ }^{28}$ There is strong immunological cross-reactivity between species: between honey bee and wasp there is 50\% sequence homology in the hyaluronidase enzymes. ${ }^{29}$ Api m 2 and Ves v 2 (hyaluronidases), and Api $m 5$ and Ves v 3 (dipeptidyl-peptidases), are well-known to cross react. ${ }^{30}$ This cross-reactivity is mainly due to CCDs exhibited in both allergen pairs, ${ }^{31}$ though they also show protein cross-reactivity. CCD-free components for in vitro diagnostic testing are Api m 1, Pol d 1 and 5, and Ves $\mathrm{v} 1$ and 5 . The venom from bees and wasps contains many different components. A list of the major venom allergens from honey bees, bumble bees, and the main wasp species is shown in Table 1 .

The major honeybee allergen is Api m 1, but unfortunately this has been shown to have low sensitivity, ${ }^{33}$ though the sensitivity can alter due to the criteria of the patient population studied. In wasp-allergic patients, rVes $v 5$ has good diagnostic performance. ${ }^{30}$ If used in conjunction with Ves $\mathrm{v} 1$, the sensitivity was significantly increased. ${ }^{34}$ The most reliable serological indicators to aid in diagnosis of true double-sensitization or cross-reactivity in patients with positive IgE results to both venom extracts are Api $\mathrm{m} 1$ and Ves v 5. ${ }^{35}$ In patients who are positive to both Polistes and Vespula, the use of Pol d 5 and Ves v 5, and Pol d 1 and Ves v 1 can be discriminatory. ${ }^{36}$

\section{Basophil activation test}

Evidence is increasing that basophil activation tests can be used to discriminate clinical reactivity, and severity of clinical reactivity, in allergic disorders. ${ }^{37,38}$ With regard to venom allergy, one study ${ }^{39}$ suggested that basophil activation tests can be useful in the setting of negative intradermal test results to complement sIgE testing when the latter is positive. 
Table I Hymenoptera venom allergens

\begin{tabular}{|c|c|c|}
\hline Venom & Allergen & Common name \\
\hline \multirow[t]{13}{*}{ Apis mellifera (honey bee) } & Api m I & Phospholipase A2 \\
\hline & Api $m 2$ & Hyaluronidase \\
\hline & Api m 3 & Acid phosphatase \\
\hline & Api $m 4$ & Melittine \\
\hline & Api $m 5$ & Allergen C \\
\hline & Api $m 6$ & Protease inhibitor \\
\hline & Api $m 7$ & Protease \\
\hline & Api m 8 & Carboxylesterase \\
\hline & Api m 9 & Carboxylesterase \\
\hline & Api m 10 & CRP \\
\hline & Api m II.0I0I & MRJP8 \\
\hline & Api m II.020I & MRJP9 \\
\hline & Api m 12 & Vitellogenin \\
\hline Bombus pennsylvanicus & Bom p I & Phospholipase A2 \\
\hline (bumble bee) & Bom p 4 & Serine protease \\
\hline \multirow[t]{6}{*}{ Vespula vulgaris (wasp) } & Ves v I & Phospholipase AI \\
\hline & Ves v 2.0101 & Hyaluronidase \\
\hline & Ves v 2.0201 & Hyaluronidase \\
\hline & Ves $\vee 3$ & DPP IV \\
\hline & Ves $\vee 5$ & Antigen 5 \\
\hline & Ves $v 6$ & Vitellogenin \\
\hline Polistes annularis (American & Pol a I & Phospholipase AI \\
\hline \multirow[t]{2}{*}{ paper wasp) } & Pol a 2 & Hyaluronidase \\
\hline & Pol a 5 & Antigen 5 \\
\hline Polistes dominula (European & Pol d I & Phospholipase AI \\
\hline \multirow[t]{2}{*}{ paper wasp) } & Pol d 4 & Protease \\
\hline & Pol d 5 & Antigen 5 \\
\hline
\end{tabular}

Notes: Data from Spillner et al. ${ }^{32}$ Adapted with permission from John Wiley and Sons. Biló BM, Rueff F, Mosbech H, Bonifazi F, Oude-Elberink JN; the EAACl Interest Group on Insect Venom Hypersensitivity. Diagnosis of Hymenoptera venom allergy. Allergy. Copyright (c) 2005 Blackwell Munksgaard 2005. ${ }^{8}$

Abbreviations: CRP, carbohydrate rich protein; MRJP, major royal jelly protein.

Another study suggested basophil activation tests may be useful for aiding the decision to cease immunotherapy. ${ }^{40}$ The emerging role of basophil activation tests in the diagnosis and management of venom allergy requires further study.

\section{Treatment of venom allergy Acute treatment of venom allergic reactions}

Acute treatment of allergic reactions to venom involves local care for LLRs including cold packs, antihistamines, NSAID gels, analgesia, or systemic corticosteroids as appropriate. SRs to venom are managed in the same way as other triggers of systemic allergic reactions. However, the rapid onset of venom allergic reactions, and the association with cardiovascular compromise, especially hypotension, mean that aggressive treatment with oxygen, intravenous fluids, and adrenaline needs to be started early. ${ }^{41,42}$ Appropriate posture may also be an important way of preventing adverse cardiac outcomes during a venom allergic reaction. ${ }^{43}$ Emergency department studies suggest that low-dose peripheral adrenaline infusion may be the optimal way to manage venom anaphylaxis, and such infusions may need to be continued for many hours. ${ }^{44}$ Older studies suggest that bolus adrenaline, even when administered intravenously, may have very limited and transient effects on cardiovascular parameters when used to treat venom anaphylaxis. ${ }^{45}$ For bee stings, removal of the sting may reduce the total dose of venom and is an important part of first aid management there is no clear evidence that any specific method for sting removal is superior. ${ }^{46}$

\section{Long-term management following a systemic venom allergic reaction}

Following recovery from an acute SR to an insect sting, provision of an adrenaline auto-injector is recommended ${ }^{47}$ although this has not been shown to improve quality of life. ${ }^{48}$ Other advice may include avoidance of high-risk activities/locations, methods for removal of stings should there be further insect stings, ${ }^{46}$ and provision of antihistamine, bronchodilator medication, and corticosteroids. For the purpose of this review, we will focus our discussion on the role of venom immunotherapy (VIT) for prevention of further allergic reactions to insect stings and promoting improved quality of life in those with a past history of significant reaction.

\section{History of VIT}

Allergen immunotherapy for hay fever was discovered at St Mary's Hospital in London by Leonard Noon in 1911, and the first randomized controlled trial of this treatment for hay fever, also at St Mary's Hospital, proved its efficacy in $1954 .{ }^{49,50}$ The first report of VIT was described in 1925, ${ }^{51}$ where the whole crushed body of a wasp was used. Wholebody extract VIT continued to be used for many years ${ }^{52}$ until it was shown to be ineffective in a randomized controlled trial. It was not until 1978 that an effective modality of VIT was developed. This used venom extracted from venom sacs, and was shown to be highly effective in a randomized controlled trial. ${ }^{53}$ Since that time, extracted venom has been used for immunotherapy with wasps, hornets, jumper ants, and honey bees. However, for fire ants, whole-body extract is still used in the US, and the latter practice has not yet been subjected to a randomized controlled efficacy trial.

In VIT, gradually increasing doses of insect venom are administered to induce immunological tolerance, typically by subcutaneous injection at an interval of several weeks for up to 5 years. Extrapolating from randomized controlled trial 
evidence in relation to hay fever, a treatment course of 3 years is recommended, although longer courses are recommended in some settings. ${ }^{4,54}$

Immunotherapy works through complex immunological mechanisms. The initial mechanism of action is a mast cell and basophil desensitization, followed by changes in T-cells (including the formation of T regulatory cells to the allergen) and finally an alteration in B-cell, IgE (an initial rise, followed by a reduction over several months), mast cell, basophil, and eosinophil responses to the allergen. ${ }^{55,56}$ Monitoring during VIT has shown a drop in sIgE and a rise in IgG4..$^{57-59}$ These immunological changes can be seen in Figure 2.

\section{VIT treatment protocols}

VIT is commercially available for honeybee, paper wasp, and yellow jacket ("European") wasps since these are the commonest causes of venom anaphylaxis worldwide. To our knowledge, immunotherapy products for ant allergy are not currently commercially available. This review will therefore focus on wasp and honeybee VIT using extracted venom. At present, the treatment offered for venom allergy is largely via subcutaneous immunotherapy (SCIT). Treatment regimes are diverse and the populations they have been tested on vary. This makes comparison between schedules difficult. However, the ability to tailor the schedule to each patient will improve efficacy and optimize safety. ${ }^{10} \mathrm{Up}$-dosing treatment protocols for subcutaneous VIT can be divided into roughly four groups which are summarized in Table 2. 10,60-62 In general, rapid up-dosing is more convenient for patients but carries increased risk of a systemic allergic reaction to treatment.

Improvement of honeybee immunotherapy efficacy may be possible by increasing the quantities of major determinants such as Api $\mathrm{m} 3$ and 10 in VIT preparation, or tailoring the allergenic component mix according to individual patient sensitization pattern. This could be done by improving the method of generating the venom preparation, spiking the venom with recombinant allergens, or tailoring the immunotherapy for different patients with a range of component allergens relevant for that patient. ${ }^{32,63,64}$

VIT starting doses are often around $0.0001 \mu \mathrm{g}$ per injection and rise to a maintenance does of $100 \mu \mathrm{g}$ (approximately two bee stings or 30 wasp stings). In children, data from a small study suggest that a lower $50 \mu \mathrm{g}$ maintenance dose provides effective protection from SRs with potentially improved safety profile. ${ }^{65}$ Longer induction-phase treatments can be done as an outpatient; however, for rush therapy, hospital admission is advisable. Although the safety profile of semi-rush and ultra-rush VIT up-dosing protocols is good, ${ }^{60,62}$ in general, accelerated up-dosing immunotherapy protocols are associated with increased risk of systemic allergic reaction to VIT. ${ }^{17}$

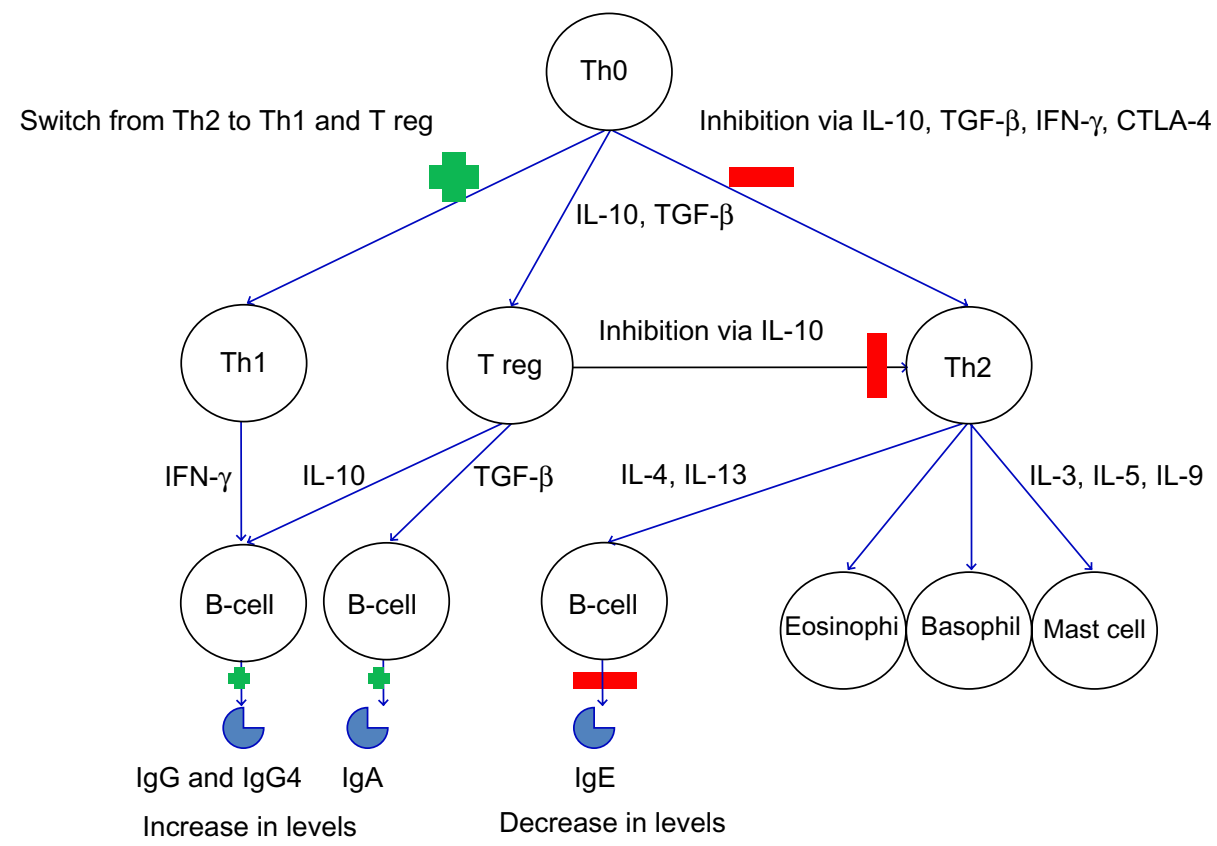

Figure 2 Immunological changes in immunotherapy.

Note: Early (4-12 weeks) changes include the induction of allergen-specific T regs. Longer-term, there is an increase in inhibitory lgG4. This final change appears to be the key for long-term tolerance induced by subcutaneous immunotherapy or sublingual immunotherapy.

Abbreviations: CTLA-4, cytotoxic T-lymphocyte-associated protein 4; IL, interleukin; IFN- $\gamma$, Interferon gamma; Ig, Immunoglobulin; TGF- $\beta$, transforming growth factor beta; Th, T helper cells; T reg, regulatory T-cells. 
Table 2 Typical VIT up-dosing protocols

\begin{tabular}{lll}
\hline & $\begin{array}{l}\text { Duration of } \\
\text { up-dosing }\end{array}$ & Dosing interval \\
\hline $\begin{array}{l}\text { Traditional/slow/ } \\
\text { conventional }\end{array}$ & $4-6$ months & $3-7$ days \\
$\begin{array}{l}\text { Semi-rush } \\
\text { Rush }\end{array}$ & 8 weeks & \\
Ultra-rush & $2-3$ weeks & 2 hours \\
Cluster/modified & 6 weeks & 20 minutes to 2 hours \\
rush & & 30 minutes to 2 injections \\
\hline
\end{tabular}

Abbreviation: VIT, venom immunotherapy.

The maintenance dose interval has historically been set at 1 month but studies have shown that intervals of up to 3-4 months retain their efficacy. ${ }^{66}$ In patients who experience SRs to stings during the traditional regime induction, accelerated induction protocols have been successfully used ${ }^{67}$ If a patient experiences a SR during maintenance VIT then a larger dose of $200 \mu \mathrm{g}$ can be given, although switching to a lower maintenance dose for a prolonged period may be needed first. ${ }^{68}$

\section{Patient selection for VIT}

VIT is recommended "as an option for the treatment of IgE-mediated bee and wasp venom allergy". ${ }^{69}$ However, guidelines vary in suggested indications for VIT. We present a summary of the major international guidelines for patient selection for VIT in Table 3 . There is significant inconsistency between guidelines, especially in relation to patients with a history of less severe local reactions or SRs. There are variations in the relative role of attempts at risk stratification through frequency of stings/severity of incident reaction versus focusing on the quality of life impact of the allergy on patients when making treatment decisions. We will discuss these specific issues below, because recent findings shed some light on considerations to be made during patient selection for VIT, and suggest the need for revised and more consistent patient-selection guidance.

Recommendations for VIT patient selection from the European Academy of Allergy and Clinical Immunology (EAACI); American Academy of Allergy, Asthma and Immunology (AAAAI); National Institute for Health and Care Excellence (NICE); and the British Society of Allergy and Clinical Immunology (BSACI) are listed in Table 3.

Contraindications for VIT also vary between guidelines. Manufacturer-stated contraindications for Pharmalgen (ALK-Abelló, Horsholm, Denmark) include malignancy, severe asthma, immunological conditions, chronic heart and lung disease, severe hypertensions, beta blockers, tricyclic antidepressants, monoamine oxidase inhibitors, angiotensinconverting enzyme inhibitors, and initiation during pregnancy (though maintenance can be continued in pregnancy) ${ }^{69}$

\section{Efficacy of VIT: reduction in SRs}

In the recent Cochrane systematic review, VIT was shown to significantly reduce risk of SR to a future sting in people who have already suffered at least one SR to a sting (relative risk [RR] $0.10,95 \%$ CI $0.03-0.28) .{ }^{17}$ From the seven trials (392 participants) included in the Cochrane review, $2.7 \%$ of patients post-VIT had a systemic allergic reaction on re-sting, compared to $39.8 \%$ untreated. ${ }^{19}$ The review included both adults and children, allergic to bee, wasp, or ant venom, and follow-up varied from months to years with re-stings triggered by either accidental field stings or intentional supervised sting challenges. One trial used sublingual (SLIT) and six trials used subcutaneous VIT, with little evidence of difference in treatment outcomes. VIT is the only specific treatment for venom allergy which can provide a reduction in morbidity. Mortality is so rare that proving VIT reduces mortality is a challenging task; however, the Cochrane review found VIT was effective across the range of reaction severity suggesting that it is likely to reduce risk of fatal venom anaphylaxis as well as nonfatal venom anaphylaxis.

The effectiveness of VIT is apparent immediately once the maintenance dose is reached. ${ }^{14}$ One study suggested a $10 \%$ reaction risk for each sting post-cessation of treatment, with a cumulative risk of a SR reaching a plateau of $20 \%$ after a decade posttreatment cessation. ${ }^{71}$ In patients not responding to VIT, it has been found that basophil activation test response to venom in vitro is associated with treatment efficacy. In patients who reacted to venom stings after completing VIT, they were found to have higher basophil responses than those who tolerated stings post-VIT. ${ }^{72}$

\section{Efficacy of VIT: reduction in LLRs}

The Cochrane review also found that VIT significantly reduces the risk of a LLR from venom (RR 0.41, 95\% CI 0.24-0.69). ${ }^{19}$ Both SCIT and SLIT VIT are effective in reducing LLRs as well as SRs. ${ }^{19}$ The role of VIT for LLRs is controversial, given the relatively low risk of serious outcomes with future stings in those with a history of LLRs. Those with troublesome recurrent LLRs, or associated anxiety or quality of life impairment through concern about further LLRs or SRs, may be considered for VIT. Although VIT is not indicated for LLRs in the EAACI and BSACI guidelines, they are cited as a relative indication in the AAAAI practice parameter (Table 3 ). 
Table 3 Patient selection for VIT - discrepancies between guidelines

\begin{tabular}{|c|c|c|c|c|}
\hline & $\mathrm{EAACl}^{8}$ & AAAA $\left.\right|^{17,58}$ & $\mathrm{NICE}^{70, *}$ & BSACl $^{4}$ \\
\hline Indications & $\begin{array}{l}\text { Respiratory and } \\
\text { cardiovascular symptoms } \\
\text { with positive skin test } \\
\text { and/or IgE } \\
\text { Urticaria if risk factors or } \\
\text { quality of life impairment } \\
\text { present with positive skin } \\
\text { tests and/or IgE }\end{array}$ & $\begin{array}{l}\text { Systemic reaction (especially } \\
\text { respiratory symptoms, } \\
\text { cardiovascular symptoms, or both) } \\
\text { to an insect sting with specific lgE } \\
\text { to venom allergens } \\
\text { Previous near-fatal anaphylactic } \\
\text { reaction to a sting } \\
\text { Patients with mastocytosis or and } \\
\text { increased baseline serum tryptase }\end{array}$ & $\begin{array}{l}\text { Severe systemic reaction to } \\
\text { bee or wasp venom } \\
\text { Moderate systemic } \\
\text { reactions with one of the } \\
\text { following: } \\
\text { - Raised baseline serum } \\
\text { tryptase } \\
\text { - High risk of future stings } \\
\text { - Anxiety about future stings }\end{array}$ & $\begin{array}{l}\text { Systemic reaction with } \\
\text { hypotension } \pm \text { laryngeal edema } \pm \\
\text { asthma } \\
\text { Must have positive venom- } \\
\text { specific IgE }\end{array}$ \\
\hline $\begin{array}{l}\text { Relative } \\
\text { indications }\end{array}$ & & $\begin{array}{l}\text { Adults who experience only } \\
\text { cutaneous manifestations to an } \\
\text { insect sting and positive specific lgE } \\
\text { are generally considered candidates } \\
\text { for VIT, although the need for VIT } \\
\text { in this group is controversial } \\
\text { Large local reaction to stings } \\
\text { but have frequent unavoidable } \\
\text { exposure }\end{array}$ & & $\begin{array}{l}\text { Mild asthma, moderate } \\
\text { angioedema, abdominal pain, } \\
\text { vomiting, diarrhea, mild } \\
\text { hypotensive symptoms (light } \\
\text { headedness, dizziness) in those } \\
\text { at risk of further stings, eg, } \\
\text { bee keeper/proximity to bees; } \\
\text { occupational exposure, eg, fruit } \\
\text { farmers, gardeners, etc } \\
\text { Other factors, eg, proximity to } \\
\text { medical help, patients' preference, } \\
\text { effect on quality of life }\end{array}$ \\
\hline Contraindications & $\begin{array}{l}\text { Large local reactions only } \\
\text { Unusual reactions } \\
\text { Negative skin tests or lgE } \\
\text { regardless of reaction }\end{array}$ & $\begin{array}{l}\text { Patients who have experienced } \\
\text { only large local reactions to stings } \\
\text { VIT is generally not necessary in } \\
\text { children } 16 \text { years old and younger } \\
\text { who have experienced cutaneous } \\
\text { systemic reactions without other } \\
\text { systemic manifestations after an } \\
\text { insect stings }\end{array}$ & & $\begin{array}{l}\text { Not usually in cutaneous } \\
\text { systemic reaction, eg, urticaria } \pm \\
\text { angioedema } \\
\text { Local reaction } \\
\text { Toxic reaction } \\
\text { Any systemic reaction, } \\
\text { independent of severity if } \\
\text { negative specific lgE }\end{array}$ \\
\hline Risk factors & $\begin{array}{l}\text { Beta blocker use is a } \\
\text { relative contraindication } \\
\text { based on risk }\end{array}$ & $\begin{array}{l}\text { Discontinue ACE inhibitors if } \\
\text { possible }\end{array}$ & & $\begin{array}{l}\text { Comorbid conditions including } \\
\text { asthma or other respiratory } \\
\text { disease, cardiac conditions, } \\
\text { and raised baseline tryptase/ } \\
\text { mastocytosis should be carefully } \\
\text { considered before making a } \\
\text { decision for VIT }\end{array}$ \\
\hline
\end{tabular}

Note: *NICE guidance refers to one specific VIT product - Pharmalgen bee and wasp venom immunotherapy (ALK-Abelló, Horsholm, Denmark) - other guidance refers to all VIT products.

Abbreviations: AAAAl, American Academy of Allergy, Asthma and Immunology; ACE inhibitor, angiotensin-converting-enzyme inhibitor; BSACl, British Society of Allergy and Clinical Immunology; EAACI, European Academy of Allergy and Clinical Immunology; IgE, Immunoglobulin E; NICE, National Institute for Health and Care Excellence; VIT, venom immunotherapy.

\section{Efficacy of VIT: quality of life}

Allergy to insect venom has been documented to cause emotional distress in patients leading to a decrease in their quality of life. ${ }^{73}$ VIT has been shown to improve the quality of life of people undergoing therapy above and beyond those who simply carry an adrenaline auto-injector (using a seven-point score where a score of 1-3 gave a positive view of treatment). The study found that patients with previous anaphylaxis had a more positive view of life after treatment (RR 2.01, 95\% CI 1.43-2.82), as well as those patients with previous cutaneous SR (RR 2.24, 95\% CI 1.13-4.43). ${ }^{19}$ These differences were seen in women and men, patients with varying degrees of baseline anxiety, and those with recent stings or stings over 1 year ago. ${ }^{48}$ It has been quoted that $72 \%$ of patients undergoing VIT derive benefit in their quality of life by undergoing treatment, ${ }^{48}$ and those who do not derive a quality of life benefit are those who have no quality of life impairment at baseline (Dr Hanneke OudeElberlink, personal communication, January 2015). The Cochrane review found that VIT improves venom-specific quality of life by a mean 1.21 points (95\% CI $0.75-1.67)$ on a seven-point scale ${ }^{19}$ (where a change of 0.5 points has been defined as the minimally important difference). ${ }^{74}$ There is also evidence suggesting that the use of a sting challenge during the maintenance phase of VIT, when tolerated, can improve quality of life..$^{75,76}$ 


\section{Adverse events associated with VIT}

Serum tryptase should be performed on patients undergoing VIT to rule out mastocytosis. ${ }^{1}$ In patients with mastocytosis, due to their significant risk of SR even after VIT and risk of anaphylaxis from other causes, continued availability of an adrenaline auto-injector is recommended following VIT. ${ }^{4}$ For all patients, there is a risk of a systemic adverse reaction during VIT; 9.3\% suffered a SR in the randomized controlled trials included in the Cochrane review. ${ }^{19}$ In a larger series of observational studies, the authors found $14.2 \%$ of people suffered a systemic allergic reaction due to a VIT injection for bee venom, and $2.8 \%$ for wasp venom. ${ }^{19}$ NICE estimated that the treatment-related adverse reaction rate is $2 \%$ per injection in the initial phase and $0.26 \%$ per injection during the maintenance phase. ${ }^{69}$ Adverse reactions are more likely with bee venom VIT, when there is a short time between sting and VIT, during up-dosing (initial) phase, in the elderly, in those using beta blockers, in clonal mast cell activation syndrome, in asthmatic children, and in those with elevated serum basal tryptase. ${ }^{10,77,78}$ Elevated serum tryptase did not lead to an increased risk of VIT failure. ${ }^{79}$

There does, however, seem to be debate about the link between length of maintenance treatment and VIT failure after a field sting. ${ }^{79,80}$ VIT failure was more likely to be linked to bee venom than wasp $(16 \%-18 \%$ versus $4 \%-7.5 \%),{ }^{80,81}$ ACE inhibitors, and systemic allergic reaction during dose increasing. ${ }^{79}$ Sting challenges are reputed to historically reveal failure of VIT in up to $22 \%$ of patients undergoing therapy. ${ }^{82}$

In the event of an LLR or SR during VIT, the recommendation is to reduce the dose to the last tolerated dose with careful dose escalation. ${ }^{4}$ However, antihistamine given pre-injections in traditional, rush, and ultra-rush VIT reduces the incidence of local reactions, and may play a role in enhancing the efficacy of immunotherapy ${ }^{83-85}$ and should be used in patients who have experienced reactions during VIT. There are a small subsection of patients who do not respond to VIT at all. There are ongoing studies at present investigating changes in gene expression in relation to response to treatment. The belief is that genetic factors may influence a patient's response to VIT and genetics may show the way to best tackle this problem. ${ }^{86}$

\section{Cost-effectiveness of VIT}

Bee venom extracts from Pharmalgen (ALK-Abelló) cost $£ 54.81$ per induction and $£ 15.94$ per maintenance injection. Wasp induction costs $£ 67.20$ and $£ 20.51$ per injection during maintenance. ${ }^{69}$ Whilst the cost varies per protocol, the average cost of a full treatment is $£ 2,299.33$ per patient. ${ }^{64}$ Cost-effectiveness of
Pharmalgen (ALK-Abelló) ${ }^{70}$ was examined in a NICE health technology assessment, in providing VIT for patients who have suffered a SR to bee or wasp venom. Four randomized controlled trials and five "quasi-experimental" small studies of poor quality were found so the authors were unable to perform meta-analysis. The clinical evidence suggested that there was a decrease in reactions to stings post-immunotherapy, but there were associated adverse reactions, some of which were systemic although all were treatable. The assessment group developed an economic model to compare cost-effectiveness of VIT with other treatment options for venom allergy.

In general, they found that VIT is not cost-effective when only considering direct costs of outcomes ${ }^{87}$ This is because for most people, recurrent insect stings are rare, and even in those with a history of severe venom allergic reaction previously, the risk of fatal outcome following a sting is extremely low. However, immunotherapy was found to be cost-effective in patients at high risk of future stings ( $\geq 3.3$ a year, for people such as bee keepers, their neighbors and children, roofers, and gardeners) and in those whom the quality of life indices show improvement with reduced anxiety. In those at high risk of a future sting (five or more stings per year) the incremental cost-effectiveness ratio of VIT with an adrenaline auto-injector and high-dose antihistamines is $£ 23,368$ per QALY (quality adjusted life year) gained when compared with high-dose antihistamine and adrenaline auto-injector alone, and $£ 25,661$ compared to avoidance advice only. These findings are summarized in Table 4.

Regarding quality of life impact, even a very small improvement in anxiety associated with treatment $(0.01$ points on the EuroQol-5 Dimension Questionnaire [EQ-5D]) makes the VIT cost-effective in the base case scenario of one sting every 9 years. This suggests that most people with a history of insect sting allergic reaction who are concerned enough to seek treatment, and are appropriately informed of the prognosis and treatment of the condition, merit consideration of VIT. Thus, focusing immunotherapy on those who are concerned, those

Table 4 Summary of Pharmalgen VIT health economic assessment $^{70}$

\begin{tabular}{ll}
\hline Model & Cost per QALY \\
\hline Base case scenario & $€ 18,065,527(€ 22,302,132)$ \\
Sting frequency $\geq 3.3$ stings per year & Cost savings from VIT \\
Sting frequency 3.I stings per year & $£ 30,000(€ 37,000)$ \\
Quality of life improvement 0.008 points & $£ 30,000(€ 37,000)$ \\
on ED-5Q with VIT & \\
\hline
\end{tabular}

Note: A threshold of $£ 30,000$ per QALY saved is used by NICE for approving therapies for use within the UK National Health Service.

Abbreviations: EQ-5D, EuroQol-5 Dimension Questionnaire; NICE, National Institute for Health and Care Excellence; QALY, quality-adjusted life year; VIT, venom immunotherapy. 
Table 5 Key areas of uncertainty for future research

Efficacy of sublingual venom immunotherapy

Optimal duration of venom immunotherapy for prolonged

treatment effect

The role of sting challenge before or after immunotherapy and effect on quality of life

Impact of venom immunotherapy in children and adolescents on quality of life

Development of improved diagnostics for venom allergy

who have documented quality of life impairment related to fear of future sting reactions, and those who have frequent insect stings is at least as important as considerations of individual risk for severe reaction based on severity of prior reaction. ${ }^{70}$

This new information, that quality of life impact is the key driver of cost in relation to venom allergy sheds some light on the discrepancies seen in the guidelines summarized in Table 3. In common with food allergy, the lives of individuals with venom allergy are overshadowed by the possibility of sudden, unexpected, rapidly fatal anaphylaxis. Such events are extremely rare, but fear of them is a major contributor to quality of life impairment and, in the case of venom allergy, quality of life can be improved by using VIT to reduce the risk of such an outcome.

If we refer back to Table 3, it is clear that VIT treatment guidelines are making an attempt to "risk stratify" patients on the basis that the decision whether or not to treat with VIT should be driven by risk of fatal or near-fatal anaphylaxis to a future sting. If one changes the paradigm, to one where quality of life is the key driver of venom allergy impact on individuals, then the "indications" for VIT change subtly. For example, the EAACI recommendation to use VIT for those with an urticarial reaction and quality of life impairment seems supported, but the AAAAI recommendation that VIT is not indicated in those aged $\leq 16$ years with a cutaneous SR to an insect sting may not be appropriate for patients who are also suffering significant quality of life impact.

\section{Future perspectives}

Ongoing research efforts are studying ways to make VIT safer, more convenient, and more widely available without compromising treatment efficacy. Table 5 highlights some uncertainties that need clarification in future research.

\section{Anti-lgE Therapy}

The use of omalizumab has been described several time during VIT for cases of recurrent anaphylaxis during treatment. ${ }^{88,89}$ It has been shown to have good efficacy in improving VIT outcomes in these situations.

\section{SLIT}

The benefit of SLIT remains its ease of administration and excellent safety profile, which make it suitable for home use. Doses used are generally higher than for SCIT, which may increase the direct pharmacy cost, but there is a cost saving and likely quality of life benefit through reduced need for supervised administration of treatment in a medical setting. ${ }^{90}$ An observational study of wasp SLIT in 21 patients showed good tolerability and suggested possible efficacy. ${ }^{91}$ An observational study of bee venom SLIT suggested reduced LLR in the majority of patients treated. ${ }^{92} \mathrm{~A}$ single randomized controlled trial of SLIT VIT was identified in the Cochrane review: ${ }^{19}$ there was no evidence that SLIT was less effective than SCIT for reducing risk of SR or LLR in that review, although this preliminary conclusion was based on a small number of studies and participants. Given the importance of quality of life improvement as an objective in VIT, highlighted by the Health Technology Assessment Programme (HTA) health economic review ${ }^{70}$ and the high burden of treatment from SCIT regimens, further investigation of SLIT as a treatment option in insect sting allergy is an important goal.

\section{Peptide immunotherapy}

Other novel techniques that have been investigated to the earliest level include the use of allergen-derived long synthetic peptides to bee venom. ${ }^{93}$ These injections proved safe and instigated T-cell hyporesponsiveness to bee venom allergen. There was also a rise in specific IgG4. A small study into the use of peptide immunotherapy in mild bee allergy found changes in surrogate markers for successful immunotherapy were exhibited suggesting that there may be benefit from this method of treating bee allergy. ${ }^{94}$ We are not aware of any further studies beyond the late 1990s into peptide immunotherapy for venom allergy.

\section{Duration of treatment}

The full length of maintenance VIT is often quoted as 3-5 years, with 5 years showing a better long-term suppression of risk. ${ }^{80,95}$ This was initially recommended because the SPT or sIgE generally was recorded as negative 3-5 years into treatment, and was extrapolated from studies of pollen immunotherapy, ${ }^{14,54}$ though there is debate about whether or not a negative intradermal test at the end of treatment is the right goal for treatment. ${ }^{80,96}$ Given the findings above, further research is needed to assess long-term quality of life in people treated for different durations. Lifelong VIT is recommended in some centers for high-risk patients 
such as those with mastocytosis or a baseline tryptase over $11.4 \mathrm{ng} / \mathrm{mL}^{97}$ due to the significantly higher risk of SRs on VIT maintenance and the higher rate of treatment failure. However, this is not supported by UK guidelines due to lack of evidence. ${ }^{4}$

The HTA health economic review ${ }^{70}$ has highlighted the importance of quality of life improvement as the primary goal of treatment, except in those at high risk of recurrent stings such as beekeepers. This means that the duration of treatment needs to be a duration which leads to quality of life improvement and suggests that 3 years may be adequate in all those other than individuals at high risk of recurrent reactions. Furthermore, the role of sting challenge as a method for providing evidence to patients that they are no longer at high risk of sting anaphylaxis merits further investigation in this context. ${ }^{75,76}$

\section{Conclusion}

Wasp and bee sting allergy can cause rapid-onset fatal anaphylaxis. Thankfully, such events are extremely rare; however, fear of such an event is a major driver of quality of life impairment in people with insect sting allergy. Venom anaphylaxis admissions in the UK appear to be increasing at a rate of $11.5 \%$ (95\% CI 10.4-12.7) per year, although fatalities remain stable.

VIT is a clinically effective treatment which should be offered to those at risk of a SR to an insect sting who have significant anxiety or quality of life impairment related to fear of future stings. A sting challenge during maintenance treatment may enhance the quality of life improvement seen with VIT. The decision whether to initiate VIT should be largely driven by considerations of quality of life impairment rather than an attempt to quantify risk of future SR, except in those such as bee keepers who suffer frequent stings.

More work is needed to clarify the role of SLIT VIT; the role of sting challenges during VIT treatment; the quality of life effect of VIT in children and adolescents, and their parents; and methods for determining the optimal duration of VIT treatment for different patient groups.

\section{Disclosure}

The authors report no conflicts of interest in this work.

\section{References}

1. Tan JW, Campbell DE. Insect allergy in children. J Paediatr Child Health. 2013;49(9):E381-E387.

2. Hoffman DR, Dove DE, Jacobson RS. Allergens in Hymenoptera venom. XX. Isolation of four allergens from imported fire ant (Solenopsis invicta) venom. J Allergy Clin Immunol. 1988;82(5 Pt 1):818-827.
3. Hoffman DR, Jacobson RS. Allergens in hymenoptera venom XII: how much protein is in a sting? Ann Allergy. 1984;52(4):276-278.

4. Krishna MT, Ewan PW, Diwakar L, et al. Diagnosis and management of hymenoptera venom allergy: British Society for Allergy and Clinical Immunology (BSACI) guidelines. Clin Exp Allergy. 2011;41(9): $1201-1220$.

5. Graft DF, Schuberth KC, Kagey-Sobotka A, et al. A prospective study of the natural history of large local reactions after Hymenoptera stings in children. J Pediatr. 1984;104(5):664-668.

6. Mauriello PM, Barde SH, Georgitis JW, Reisman RE. Natural history of large local reactions from stinging insects. J Allergy Clin Immunol. 1984;74(4 Pt 1):494-498.

7. Golden DB, Kelly D, Hamilton RG, Craig TJ. Venom immunotherapy reduces large local reactions to insect stings. J Allergy Clin Immunol. 2009;123(6):1371-1375.

8. Biló BM, Rueff F, Mosbech H, Bonifazi F, Oude-Elberink JN; the EAACI Interest Group on Insect Venom Hypersensitivity. Diagnosis of Hymenoptera venom allergy. Allergy. 2005;60(11):1339-1349.

9. Pumphrey RS. Lessons for management of anaphylaxis from a study of fatal reactions. Clin Exp Allergy. 2000;30(8):1144-1150.

10. Antolín-Amérigo D, Moreno Aguilar C, Vega A, Alvarez-Mon M. Venom immunotherapy: an updated review. Curr Allergy Asthma Rep. 2014;14(7):449.

11. Golden DB, Kagey-Sobotka A, Norman PS, Hamilton RG, Lichtenstein LM. Outcomes of allergy to insect stings in children, with and without venom immunotherapy. $N$ Engl J Med. 2004;351(7): 668-674.

12. Turner PJ, Gowland MH, Sharma V, et al. Increase in anaphylaxisrelated hospitalizations but no increase in fatalities: an analysis of United Kingdom national anaphylaxis data, 1992-2012. JAllergy Clin Immunol. 2015;135(4):956-963. e1.

13. Graft DF. Insect sting allergy. Med Clin North Am. 2006;90(1): 211-232.

14. Bilò MB. Anaphylaxis caused by Hymenoptera stings: from epidemiology to treatment. Allergy. 2011;66 Suppl 95:35-37.

15. Worm M, Moneret-Vautrin A, Scherer K, et al. First European data from the network of severe allergic reactions (NORA). Allergy. 2014; 69(10):1397-1404

16. Xie C, Xu S, Ding F, et al. Clinical features of severe wasp sting patients with dominantly toxic reaction: analysis of 1091 cases. PloS One. 2013;8(12):e83164.

17. Golden DB, Moffitt J, Nicklas RA, et al. Stinging insect hypersensitivity: a practice parameter update 2011. J Allergy Clin Immunol. 2011;127(4): 852-8544. e1-e23.

18. Ruëff F, Przybilla B, Biló MB, et al. Predictors of severe systemic anaphylactic reactions in patients with Hymenoptera venom allergy: importance of baseline serum tryptase-a study of the European Academy of Allergology and Clinical Immunology Interest Group on Insect Venom Hypersensitivity. J Allergy Clin Immunol. 2009;124(5):1047-1054.

19. Boyle RJ, Elremeli M, Hockenhull J, et al. Venom immunotherapy for preventing allergic reactions to insect stings. Cochrane Database Syst Rev. 2012;10:CD008838.

20. Yavuz ST, Sahiner UM, Buyuktiryaki B, et al. Clinical features of children with venom allergy and risk factors for severe systemic reactions. Int Arch Allergy Immunol. 2013;160(3):313-321.

21. Pucci S, De Pasquale T, D'Alò S, Illuminati I, Makrì E, Incorvaia C. Systemic reactions to honeybee stings and nonsteroidal antinflammatory drugs. Ann Allergy Asthma Immunol. 2014;113(2):237-238.

22. Wood RA, Camargo CA Jr, Lieberman P, et al. Anaphylaxis in America: the prevalence and characteristics of anaphylaxis in the United States. J Allergy Clin Immunol. 2014;133(2):461-467.

23. Baker TW, Forester JP, Johnson ML, Stolfi A, Stahl MC. The HIT study: Hymenoptera Identification Test - how accurate are people at identifying stinging insects? Ann Allergy Asthma Immunol. 2014;113(3): 267-270.

24. Sturm GJ, Kranzelbinder B, Schuster C, et al. Sensitization to Hymenoptera venoms is common, but systemic sting reactions are rare. J Allergy Clin Immunol. 2014;133(6):1635-1643. e1. 
25. Portnoy JM, Moffitt JE, Golden DB, et al. Stinging insect hypersensitivity: a practice parameter. The Joint Force on Practice Parameters, the American Academy of Allergy, Asthma and Immunology, the American College of Allergy, Asthma and Immunology, and the Joint Council of Allergy, Asthma and Immunology. J Allergy Clin Immunol. 1999; 103(5 Pt 1):963-980.

26. Strohmeier B, Aberer W, Bokanovic D, Komericki P, Sturm GJ. Simultaneous intradermal testing with hymenoptera venoms is safe and more efficient than sequential testing. Allergy. 2013;68(4): $542-544$

27. Treudler R, Simon JC. Overview of component resolved diagnostics. Curr Allergy Asthma Rep. 2013;13(1):110-117.

28. Product Catalog 2012 - ImmunoCAP: Is it allergy? Waltham: Thermo Fisher Scientific; 2012. Available from: http://www.phadia com/Global/A\%20Document\%20Library/Product\%20Catalogues/ ProdCat2012_ID_AI.pdf. Accessed March 10, 2015.

29. Reisman RE, Müller UR, Wypych JI, Lazell MI. Studies of coexisting honeybee and vespid-venom sensitivity. J Allergy Clin Immunol. 1984;73(2):246-252.

30. Müller UR, Johansen N, Petersen AB, Fromberg-Nielsen J, Haeberli G. Hymenoptera venom allergy: analysis of double positivity to honey bee and Vespula venom by estimation of $\mathrm{IgE}$ antibodies to species-specific major allergens Api m1 and Ves v5. Allergy. 2009;64(4):543-548.

31. Mittermann I, Zidarn M, Silar M, et al. Recombinant allergen-based IgE testing to distinguish bee and wasp allergy. J Allergy Clin Immunol. 2010;125(6):1300-1307. e3.

32. Spillner E, Blank S, Jakob T. Hymenoptera allergens: from venom to "venome". Front Immunol. 2014;5:77.

33. Korošec P, Valenta R, Mittermann I, et al. Low sensitivity of commercially available rApi $\mathrm{m} 1$ for diagnosis of honeybee venom allergy. J Allergy Clin Immunol. 2011;128(3):671-673.

34. Seismann H, Blank S, Cifuentes L, et al. Recombinant phospholipase A1 (Ves v 1) from yellow jacket venom for improved diagnosis of hymenoptera venom hypersensitivity. Clin Mol Allergy. 2010;8:7.

35. Eberlein B, Krischan L, Darsow U, Ollert M, Ring J. Double positivity to bee and wasp venom: improved diagnostic procedure by recombinant allergen-based IgE testing and basophil activation test including data about cross-reactive carbohydrate determinants. JAllergy Clin Immunol. 2012;130(1):155-161.

36. Monsalve RI, Vega A, Marqués L, et al. Component-resolved diagnosis of vespid venom-allergic individuals: phospholipases and antigen $5 \mathrm{~s}$ are necessary to identify Vespula or Polistes sensitization. Allergy. 2012;67(4):528-536.

37. Santos AF, Du Toit G, Douiri A, et al. Distinct parameters of the basophil activation test reflect the severity and threshold of allergic reactions to peanut. J Allergy Clin Immunol. 2015;135(1): 179-86.

38. Santos AF, Douiri A, Bécares N, et al. Basophil activation test discriminates between allergy and tolerance in peanut-sensitized children J Allergy Clin Immunol. 2014;134(3):645-652.

39. Bonadonna P, Zanotti R, Melioli G, et al. The role of basophil activation test in special populations with mastocytosis and reactions to hymenoptera sting. Allergy. 2012;67(7):962-965.

40. González-de-Olano D, Alvarez-Twose I, Morgado JM, et al. Evaluation of basophil activation in mastocytosis with Hymenoptera venom anaphylaxis. Cytometry B Clin Cytom. 2011;80(3):167-175.

41. Working Group of the Resuscitation Council (UK). Emergency Treatment of Anaphylactic Reactions. Guidelines for Healthcare Providers. London: Resuscitation Council (UK); 2008. Available from: http://www. resus.org.uk/pages/reaction.pdf. Accessed March 10, 2015.

42. Muraro A, Roberts G, Worm M, et al. Anaphylaxis: guidelines from the European Academy of Allergy and Clinical Immunology. Allergy. 2014;69(8):1026-1045.

43. Pumphrey RSH. Fatal posture in anaphylactic shock. J Allergy Clin Immunol. 2003;112(2):451-452.

44. Brown SG, Blackman KE, Stenlake V, Heddle RJ. Insect sting anaphylaxis; prospective evaluation of treatment with intravenous adrenaline and volume resuscitation. Emerg Med J. 2004;21(2):149-154.
45. Smith PL, Kagey-Sobotka A, Bleecker ER, et al. Physiologic manifestations of human anaphylaxis. J Clin Invest. 1980;66(5):1072-1080.

46. Visscher PK, Vetter RS, Camazine S. Removing bee stings. Lancet. 1996;348(9023):301-302.

47. Howdle P. NICE clinical guideline 134. Anaphylaxis: assessment to confirm an anaphylactic episode and the decision to refer after emergency treatment for a suspected anaphylactic episode [webpage on the Internet]. London: National Institute for Health and Care Excellence; 2011. Available from: http://www.nice.org.uk/guidance/CG134. Accessed March $10,2015$.

48. Oude Elberink JN, De Monchy JG, Van Der Heide S, Guyatt GH, Dubois AE. Venom immunotherapy improves health-related quality of life in patients allergic to yellow jacket venom. JAllergy Clin Immunol. 2002;110(1):174-182.

49. Noon L. Prophylactic inoculation against hay fever. Lancet. 1911; 177(4580):1572-1573.

50. Frankland AW, Augustin R. Prophylaxis of summer hay-fever and asthma: a controlled trial comparing crude grass-pollen extracts with the isolated main protein component. Lancet. 1954;266(6821):1055-1057.

51. Braun L. Notes on desensitisation of a patient hypersensitive to bee stings. South Afr Med Rec. 1925;(23):408-409.

52. Jutel M, Akdis CA. Immunological mechanisms of allergen-specific immunotherapy. Allergy. 2011;66(6):725-732.

53. Hunt KJ, Valentine MD, Sobotka AK, Benton AW, Amodio FJ, Lichtenstein LM. A controlled trial of immunotherapy in insect hypersensitivity. N Engl J Med. 1978;299(4):157-161.

54. Durham SR, Walker SM, Varga EM, et al. Long-term clinical efficacy of grass-pollen immunotherapy. $N$ Engl J Med. 1999;341(7):468-475.

55. Ewan PW. New insight into immunological mechanisms of venom immunotherapy. Curr Opin Allergy Clin Immunol. 2001;1(4): 367-374.

56. Akdis M, Akdis CA. Mechanisms of allergen-specific immunotherapy. J Allergy Clin Immunol. 2007;119(4):780-791.

57. Hayashi $Y$, Hirata $H$, Watanabe $M$, et al. Usefulness of specific-IgG4 to Hymenoptera venom in the natural history of hymenoptera stings. J Investig Allergol Clin Immunol. 2014;24(3):192-194.

58. Cox L, Nelson H, Lockey R, et al. Allergen immunotherapy: a practice parameter third update. J Allergy Clin Immunol. 2011;127(1 Suppl): S1-S55.

59. Goldberg A, Confino-Cohen R. Bee venom immunotherapy - how early is it effective? Allergy. 2010;65(3):391-395.

60. Brown SG, Wiese MD, van Eeden P, et al. Ultrarush versus semirush initiation of insect venom immunotherapy: a randomized controlled trial. J Allergy Clin Immunol. 2012;130(1):162-168.

61. Brehler R, Wolf H, Kütting B, Schnitker J, Luger T. Safety of a two-day ultrarush insect venom immunotherapy protocol in comparison with protocols of longer duration and involving a larger number of injections. J Allergy Clin Immunol. 2000;105(6 Pt 1):1231-1235.

62. Birnbaum J, Charpin D, Vervloet D. Rapid Hymenoptera venom immunotherapy: comparative safety of three protocols. Clin Exp Allergy. 1993;23(3):226-230.

63. Köhler J, Blank S, Müller S, et al. Component resolution reveals additional major allergens in patients with honeybee venom allergy. J Allergy Clin Immunol. 2014;133(5):1383-1389, 1389. e1-e6.

64. Golden DB. New directions in diagnostic evaluation of insect allergy. Curr Opin Allergy Clin Immunol. 2014;14(4):334-339.

65. Konstantinou GN, Manoussakis E, Douladiris N, et al. A 5-year venom immunotherapy protocol with $50 \mu \mathrm{g}$ maintenance dose: safety and efficacy in school children. Pediatr Allergy Immunol. 2011;22(4) 393-397.

66. Simioni L, Vianello A, Bonadonna P, et al. Efficacy of venom immunotherapy given every 3 or 4 months: a prospective comparison with the conventional regimen. Ann Allergy Asthma Immunol. 2013;110(1): 51-54.

67. Goldberg A, Confino-Cohen R. Rush venom immunotherapy in patients experiencing recurrent systemic reactions to conventional venom immunotherapy. Ann Allergy Asthma Immunol. 2003;91(4): $405-410$. 
68. Ruëff F, Wenderoth A, Przybilla B. Patients still reacting to a sting challenge while receiving conventional Hymenoptera venom immunotherapy are protected by increased venom doses. JAllergy Clin Immunol. 2001;108(6):1027-1032.

69. Adler A. Pharmalgen for the Treatment of Bee and Wasp Venom Allergy: Technology Appraisal Guidance [TA246] [webpage on the Internet]. London: National Institute for Health and Care Excellence; 2012 [cited January 27, 2015]. Available from: https:/www.nice.org.uk/guidance/ ta246. Accessed March 10, 2015.

70. Hockenhull J, Elremeli M, Cherry MG, et al. A systematic review of the clinical effectiveness and cost-effectiveness of Pharmalgen ${ }^{\circledR}$ for the treatment of bee and wasp venom allergy. Health Technol Assess. 2012;16(12):III-IV, 1-110.

71. Golden DB, Kagey-Sobotka A, Lichtenstein LM. Survey of patients after discontinuing venom immunotherapy. J Allergy Clin Immunol. 2000;105(2 Pt 1):385-390.

72. Peternelj A, Silar M, Erzen R, Kosnik M, Korosec P. Basophil sensitivity in patients not responding to venom immunotherapy. Int Arch Allergy Immunol. 2008;146(3):248-254.

73. Oude Elberink JN, de Monchy JG, Golden DB, Brouwer JL, Guyatt GH, Dubois AE. Development and validation of a health-related quality-oflife questionnaire in patients with yellow jacket allergy. J Allergy Clin Immunol. 2002;109(1):162-170.

74. Oude Elberink JN, van der Heide S, Guyatt GH, Dubois AE. Immunotherapy improves health-related quality of life of adult patients with dermal reactions following yellow jacket stings. Clin Exp Allergy. 2009;39(6):883-889.

75. Koschel DS, Schmies M, Weber CN, Höffken G, Balck F. Tolerated sting challenge in patients on Hymenoptera venom immunotherapy improves health-related quality of life. J Investig Allergol Clin Immunol. 2014;24(4):226-230.

76. Fischer J, Teufel M, Feidt A, Giel KE, Zipfel S, Biedermann T. Tolerated wasp sting challenge improves health-related quality of life in patients allergic to wasp venom. J Allergy Clin Immunol. 2013;132(2): 489-490.

77. Yavuz ST, Sahiner UM, Buyuktiryaki B, et al. PD41 - Risk factors for side effects during venom immunotherapy in children with hymenoptera venom allergy. Clin Transl Allergy. 2014;4:P41.

78. Ruëff F, Przybilla B, Biló MB, et al. Predictors of side effects during the buildup phase of venom immunotherapy for Hymenoptera venom allergy: the importance of baseline serum tryptase. J Allergy Clin Immunol. 2010;126(1):105-111. e5.

79. Ruëff F, Przybilla B, Biló MB, et al. Clinical effectiveness of hymenoptera venom immunotherapy: a prospective observational multicenter study of the European academy of allergology and clinical immunology interest group on insect venom hypersensitivity. PLoS One. 2013;8(5):e63233.

80. Lerch E, Müller UR. Long-term protection after stopping venom immunotherapy: results of re-stings in 200 patients. J Allergy Clin Immunol. 1998;101(5):606-612.

81. Müller U, Helbling A, Berchtold E. Immunotherapy with honeybee venom and yellow jacket venom is different regarding efficacy and safety. J Allergy Clin Immunol. 1992;89(2):529-535.
82. Ruëff F, Przybilla B, Müller U, Mosbech H. The sting challenge test in Hymenoptera venom allergy. Position paper of the Subcommittee on Insect Venom Allergy of the European Academy of Allergology and Clinical Immunology. Allergy. 1996;51(4):216-225.

83. Berchtold E, Maibach R, Müller U. Reduction of side effects from rush-immunotherapy with honey bee venom by pretreatment with terfenadine. Clin Exp Allergy. 1992;22(1):59-65.

84. Müller U, Hari Y, Berchtold E. Premedication with antihistamines may enhance efficacy of specific-allergen immunotherapy. J Allergy Clin Immunol. 2001;107(1):81-86.

85. Brockow K, Kiehn M, Riethmüller C, Vieluf D, Berger J, Ring J. Efficacy of antihistamine pretreatment in the prevention of adverse reactions to Hymenoptera immunotherapy: a prospective, randomized, placebo-controlled trial. J Allergy Clin Immunol. 1997;100(4): 458-463.

86. Niedoszytko M, Gruchała-Niedoszytko M, Jassem E. Gene expression analysis in allergology: the prediction of Hymenoptera venom allergy severity and treatment efficacy. Clin Transl Allergy. 2013;3(1):35.

87. Boyle RJ, Dickson R, Hockenhull J, Cherry MG, Elremeli M. Immunotherapy for Hymenoptera venom allergy: too expensive for European health care? Allergy. 2013;68(10):1341-1342.

88. Galera C, Soohun N, Zankar N, Caimmi S, Gallen C, Demoly P. Severe anaphylaxis to bee venom immunotherapy: efficacy of pretreatment and concurrent treatment with omalizumab. J Investig Allergol Clin Immunol. 2009;19(3):225-229.

89. Palgan K, Bartuzi Z, Gotz-Zbikowska M. Treatment with a combination of omalizumab and specific immunotherapy for severe anaphylaxis after a wasp sting. Int J Immunopathol Pharmacol. 2014;27(1):109-112.

90. Cox L, Compalati E, Kundig T, Larche M. New directions in immunotherapy. Curr Allergy Asthma Rep. 2013;13(2):178-195.

91. Patriarca G, Nucera E, Roncallo C, et al. Sublingual desensitization in patients with wasp venom allergy: preliminary results. Int $J$ Immunopathol Pharmacol. 2008;21(3):669-677.

92. Severino MG, Cortellini G, Bonadonna P, et al. Sublingual immunotherapy for large local reactions caused by honeybee sting: a double-blind, placebo-controlled trial. J Allergy Clin Immunol. 2008;122(1):44-48.

93. Fellrath JM, Kettner A, Dufour N, et al. Allergen-specific T-cell tolerance induction with allergen-derived long synthetic peptides: results of a phase I trial. J Allergy Clin Immunol. 2003;111(4):854-861.

94. Tarzi M, Klunker S, Texier C, et al. Induction of interleukin-10 and suppressor of cytokine signalling-3 gene expression following peptide immunotherapy. Clin Exp Allergy. 2006;36(4):465-474.

95. Keating MU, Kagey-Sobotka A, Hamilton RG, Yunginger JW. Clinical and immunologic follow-up of patients who stop venom immunotherapy. J Allergy Clin Immunol. 1991;88(3 Pt 1):339-348.

96. Golden DB. Fatal insect allergy after discontinuation of venom immunotherapy. J Allergy Clin Immunol. 2001;107(5):925-926.

97. Ebo DG, Van Vaerenbergh M, de Graaf DC, Bridts CH, De Clerck LS, Sabato V. In vitro diagnosis of Hymenoptera venom allergy and further development of component resolved diagnostics. Expert Rev Clin Immunol. 2014;10(3):375-384
Journal of Asthma and Allergy

\section{Publish your work in this journal}

The Journal of Asthma and Allergy is an international, peer-reviewed open-access journal publishing original research, reports, editorials and commentaries on the following topics: Asthma; Pulmonary physiology; Asthma related clinical health; Clinical immunology and the immunological basis of disease; Pharmacological interventions and

new therapies. Issues of patient safety and quality of care will also be considered. The manuscript management system is completely online and includes a very quick and fair peer-review system, which is all easy to use. Visit http://www.dovepress.com/testimonials.php to read real quotes from published authors.

\section{Dovepress}

Submit your manuscript here: http://www.dovepress.com/journal-of-asthma-and-allergy-journal 